\title{
The Types and Needs of Academic Library Users: A Case Study of 6,568 Responses
}

\begin{abstract}
Responses to a Library User's Questionnaire were analyzed by use of a chi-square statistic to determine whether the faculty, graduate students, and undergraduates were homogeneous with respect to their primary and secondary reasons for visiting the library, and also with respect to the library materials used.
\end{abstract}

$I_{1}$

F IT WERE POSSIBLE to divide the total population of library users into subpopulations based on their needs, academic library administrators could better predict the responses of these user groups to proposed programs or changes. Programs might be developed aimed specifically at satisfying needs of a particular group. Thus it is desirable to identify functionally different user groups, not only to gauge library effectiveness but also to guide its programs. In a recent survey conducted in an academic library, faculty and student users (i.e., library "visitors") were asked to evaluate the library's services. To discover their attitudes and certain descriptive information about respondents, a special questionnaire was designed and directed to a sampling of users at all levels. The response of users was excellent, and 6,568 gave the information request-

Mr. Rzasa and Mr. Moriarty are participants in the Purdue University Engineering Analysis of Information Service Systems Project, supported in part by NSF Grant GN 2394. ed by the survey questionnaire.

It is assumed that different users visit the library for different purposes but that it is also possible to identify general types of users. One possible and conventional classification divides users into four categories: faculty, graduate students, undergraduates, and others. It was hypothesized that by such grouping, the library could determine whether a significant difference exists among the groups based upon their needs for library materials. If there are such differences in group needs or preferences, the library may then be able to focus new programs on the needs of the various groups. More specifically, if the university decided to build its undergraduate programs, the library administration could focus attention on needs of the undergraduate students and develop plans, programs, and budgets to satisfy these needs. On the other hand, if the university focused on the growth of the

- See Appendix. The assistance of Dr. Warren Seibert, Instructional Media Research Unit, Purdue University, in all phases of work on this questionnaire is gratefully acknowledged. 
graduate programs, then plans, services, and budgets should be developed to satisfy these needs. For example, one likely difference between the library needs of graduate students and undergraduates is that graduate students prefer to seek periodicals and journals for the more current developments in their fields of interest, whereas undergraduates prefer books more for the history and a general knowledge of their field of interest. ${ }^{1}$ However, only the examination of the data from a very detailed Library User's Questionnaire can sharpen the determination of the specific types, number, and appropriate weighting of needs of the users.

\section{The Questionnaire}

The Library User's Questionnaire consisted of thirteen questions with response alternatives for each question. The users responded by selecting the alternatives most accurate or descriptive for them and by marking the corresponding space on an IBM mark-sensed card. The number of alternatives for each question varied from six to twelve.

The first question dealt with the user's present relation to the university: professor, associate professor, assistant professor, instructor, Ph.D. student, master's student, senior, junior, sophomore, freshman, staff, and those not associated with the university. For the analysis, the responses from professors, associate professors, assistant professors, and instructors were combined to form a faculty group; Ph.D. and master's students formed the graduate student group; and seniors, juniors, sophomores, and freshmen formed the undergraduate student group. Staff members and persons not associated with the university were not included in the analysis.

The questionnaire's second question, dealing with the length of time the user was employed by or attending the university was not considered of impor- tance because, except for the faculty, a relationship exists between the student classification and the number of years at the university.

The third question dealt with the principal field of study or the "major" of the respondent. The breakdown of possible responses was essentially by broad fields or classes descriptive of schools and/or related areas of study: e.g., engineering, physical sciences, and history or political science.

The fourth question dealt with the frequency of the respondent's visits to the library. The alternatives ranged from "at least once daily" to "less than once a month."

The fifth question asked the respondent to indicate his principal reason for coming to the library that day. Responses to this question should have indicated to the library administration: 1) why most of the users came to the library; and 2) the differences, if any, in the purposes of groups of users. An indepth analysis of the responses to question five should have enabled the library administrator to discover the main reasons patrons use the library facilities.

The sixth question asked respondents their secondary reasons for coming to the library. The combination of questions five and six should thus have given good indication of the user's reasons for coming to the library. If, for example, few people came to the library to read for pleasure and if the library administration wished to increase the number of such readers, it should develop programs directed toward attainment of this goal. The library might conduct an advertising campaign to publicize the pleasures of reading or it might increase and keep current the amount of reading material for recreation.

The seventh and eighth questions dealt with the principal (or "main") materials and the secondary or other materials respondents used in the library. These two questions can be considered 
the most important in the survey, since they reveal which materials are sought from the library. If one considers that the primary goal of a library is to provide materials to satisfy users' needs, then the identification of that material and/or information which satisfies a user's needs implies that it should be contained within the library system. If, of course, the material and/or information sought by users is not within the library system, then plans and programs should be developed to insure their presence.

Questions nine through thirteen dealt with the user's evaluation of the library's physical condition and the library's ability to satisfy its patrons. The responses varied in five steps from "excellent" to "very poor" and included the alternative, "the question does not apply."

\section{Analysis}

The first analysis of the Library User's Questionnaire was a series of chisquare statistical tests to determine whether the distributions of the users' principal reasons for coming to the library differed for faculty, graduate students, and undergraduates. The raw data were in the form of a stratified sample and percentages were given, i.e., the sum total of responses of full professors was 100 percent; of associate professors was 100 percent; and of assistant professors was 100 percent. To evaluate the data in this form, a com- puter program was written which combined responses of the faculty into one column, responses of graduate students into a second column, and responses of undergraduates into a third column, and which then performed a chi-square analysis. The program for questions five, six, seven, and eight can be secured from the authors. The total usable sample size was 6,323 .

The formula which can be used when the data are in the form of percentages is that suggested by Walker and Lev. ${ }^{2}$ (See formula below.)

The hypothesis for question five is that the distribution of users' principal reasons for visiting the library is the same for all three groups: faculty, graduate students, and undergraduates. If the hypothesis is accepted, it would mean that these three groups are homogenous with respect to their principal reasons for coming to the library. For analysis of the question, responses $5 \mathrm{e}$, $5 \mathrm{f}$, and $5 \mathrm{~g}$ were combined to insure that the $P_{i j}$ value would be greater than zero. With $\mathrm{r}$ designating the number of rows and $c$ designating the number of columns, a chi-square value with $(\mathrm{r}-1)$ (c-1) degrees of freedom, (8) $(2)=16$ degrees of freedom, and a probability of acceptance of .999 is 39.3 . The chisquare value calculated for the responses of the faculty, graduate students, and undergraduate students is 1,910 . Thus, the hypothesis that the different groups are homogeneous with respect to their principal reasons for visiting the library is rejected.

$$
\mathrm{X}^{2}=N\left(\underset{\mathrm{i} j}{\Sigma} \frac{\mathrm{p}_{\mathrm{j}}}{\mathrm{p}_{\mathrm{ij}}}-1\right)
$$

where $\mathrm{N}=$ the total sample size

$\mathrm{p}_{\mathrm{ij}}=$ the observed proportion in the ij cell

$\mathrm{p}_{\mathrm{ij}}=$ the expected proportion in the ij cell $=\left(\mathrm{p}_{\mathrm{i}}\right)\left(\mathrm{p}_{\mathrm{j} . \mathrm{j}}\right)$

$p_{i .}=\Sigma p_{i j}$ the row total

$\mathrm{p}_{. j}=\underset{\mathbf{i}}{\sum_{i}^{j}} \mathrm{p}_{\mathrm{ij}}$ the column total 
It should be noted that the largest response category for faculty respondents was "to do research for a publishable paper or book" (21 percent), while more than 50 percent of the faculty came to do research for a publishable paper, "read library material for selfimprovement," or "find and read material required for a course."

The largest response category for the graduate students was to "find and read material required for a course" (30 percent), while more than 65 percent of the graduate students came to "find and read material required for a course," "do homework with own books," or "do research for graduate exams or thesis."

The largest response category for the undergraduate was "to do homework with own books" (over 50 percent) and over 72 percent came to "do homework with own books" or "find and read material required for a course."

The hypothesis for question six is that the distribution of users' secondary reasons for coming to the library is the same for faculty, graduate students, and undergraduates. For the analysis, responses $6 \mathrm{e}, 6 \mathrm{f}$, and $6 \mathrm{~g}$ were combined to insure that the $P_{i j}$ value would be greater than zero. A chi-square value with (r-1) (c-1) degrees of freedom, $(9)(2)=18$ degrees of freedom, and a probability of acceptance of .999 is 42.3. The chi-square value calculated for responses to the question was 527 . The hypothesis that the three different groups are homogeneous with respect to their secondary reasons for visiting the library is rejected. It should be noted also that, of all the users, 43 percent reported no secondary reason for their library visit.

The most common response of the faculty to question six indicated "no secondary reason" for their visit, while the two most common responses were to "borrow material for later reading," and "read material for self-improvement." These three responses accounted for over 63 percent of all faculty responses to the question.

The most common response of the graduate students indicated "no secondary reason" (32 percent), while the three next most common responses were to "find and read material required for a course," "do homework with own books," and "read library material for self-improvement." These four responses accounted for over 66 percent of the graduate student responses.

The most common response of the undergraduates again indicated "no secondary reason" (48 percent), while the next most common response was to "do homework with own books." The two responses accounted for over 65 percent of the undergraduates' responses.

The hypothesis for question seven is that the distribution of the primary library materials used is the same for faculty, graduate students, and undergraduate users. For the analysis of the question, responses $7 \mathrm{e}, 7 \mathrm{f}, 7 \mathrm{~g}$, and $7 \mathrm{~h}$ were combined to insure that $\mathrm{P}_{\mathrm{ij}}$ value was greater than zero. A chi-square value with $(\mathrm{r}-1)(\mathrm{c}-1)$ degrees of freedom, $(9)(2)=18$ degrees of freedom, and a probability of acceptance of .999 is 42.3. The chi-square value calculated for responses is 1,163 . The hypothesis that the three different groups are homogeneous with respect to the primary library materials used is thus rejected.

The four most common faculty responses to question seven, which accounted for over 75 percent of their responses, were scholarly journals or periodicals, reference books, books, monographs and individual works, and reserve books. The four largest responses, accounting for more than 70 percent of the graduate student responses, were scholarly journals or periodicals, reserve books, reference books, and books, monographs, and individual works.

As mentioned in the discussion of question five, more than 50 percent of the undergraduates brought their own 
materials. The two next most common responses, each over 25 percent, were for reserve books and reference books.

The hypothesis for question eight is that the distribution of the "secondary or other" library materials used is the same for faculty, graduate students, and undergraduates. As in question seven, responses $8 \mathrm{e}, 8 \mathrm{f}, 8 \mathrm{~g}$, and $8 \mathrm{~h}$ were combined. The chi-square for 18 degrees of freedom and a probability of acceptance of .999 is 42.3 . The chisquare calculated for the responses to question 8 was 394 . Therefore, the hypothesis is rejected.

In the responses to the question, it should be noted that about 58 percent of all users did not use secondary materials. This may account for the low value of the calculated chi-square as compared with the values for earlier questions.

The two largest responses of the faculty, representing over 25 percent, were due to reference books, and scholarly journals or periodicals. The largest response was that "no other materials" were used, representing over 41 percent of the respondents.

The two most common responses of the graduates chosen, by more than 25 percent, were also for scholarly journals or periodicals, and reference books. More than 42 percent of the graduates reportedly used no other materials.

The three most common responses of the undergraduates, with over 17 percent responding, were for reference books, scholarly journals or periodicals, and reserve books. Over 63 percent of the undergraduates did not use other materials.

\section{Implications of User Response}

In the previous section, it was seen that the faculty group, the graduate student group, and the undergraduates were not homogeneous with respect to their reasons for coming to the library, nor in the library materials which they used. Let us now consider the similarities and dissimilarities among the groups, given their responses to the questionnaire.

The main interests of the faculty for using the library facilities were to do research for a publishable paper and to read for self-improvement. There was little or no overlap of these interests with those of the two student groups. On the other hand, the third largest response of the faculty (to read material required for a course) was the main interest of the graduate students ( 30 percent) for both their primary and secondary reasons for coming to the library. Course requirements were the second largest need of the undergraduates. This suggests that programs aimed at providing material required for courses would help satisfy needs of all three user groups. The largest response category (in terms of a percentage of a group and the number of users) was to do homework with their own books. Over 50 percent of the undergraduates gave this response as a primary reason, and an additional 17 percent gave it as a secondary reason. This category was also the second largest for the graduate students. These results indicate that the library should either plan to provide sufficient study space for the student groups or, together with the university community, plan to provide appropriate study halls elsewhere on the campus.

Scholarly journals and periodicals are the primary materials used by both faculty and graduate students. Therefore it might be expected that increased expenditures for these materials would help to satisfy the primary needs of the faculty and graduates but would not necessarily satisfy the primary or secondary needs of the undergraduates. Reserve books and reference books are the other materials desired by all three user groups. This would imply that the library administration should focus on 
both of these. Programs which consider the placement and removal of books to and from the reserve list might be beneficial.

\section{REFERENCES}

1. Trueswell, R. W., "User Behavioral Pat- terns and Requirements and Their Effect on the Possible Applications of Data Processing and Techniques in a University Library," Ph.D. Thesis, Northwestern University, 1964.

2. Walker, H. M., and Lev, J., Statistical Inference (New York: Henry Holt and Company, 1953), p.97.

\section{APPENDIX}

\section{LiBRARY UsER'S QUESTIONNAIRE}

Your help is requested. Just before you leave the library, please take three or four minutes to answer the questions below. Your answers will help us to understand the library interests and opinions of the faculty, students, and others. MARK YOUR ANSWERS ON THE IBM CARD, USING THE SPECIAL (SOFT) PENCIL YOU RECEIVED. For each question, locate the response that is most accurate or descriptive for you and mark the corresponding space on the IBM card. Please record only one answer to each question. The University Trustees have authorized this questionnaire as part of a library's survey.

1. I am a:
A Professor
B Associate Professor
C Assistant Professor
D Instructor
E Ph.D. student
F Master's student
G Senior
$\mathrm{H}$ Junior
I Sophomore
J Freshman
K Staff member

L Person not with the university

2. I have been employed by or am attending the university:
A Less than 1 year
B 1 or 2 years
C 3 or 4 years
D 5 or 6 years
E 7 or 8 years
F 9 or 10 years
G 11 to 15 years
$\mathrm{H} 16$ to 20 years
I 21 years or more
J The question does not apply

3. My principal field of study or my "major" may be classed as:
A Agriculture
B Biological Sciences
C Economics-Business Administration
D Education
E Engineering

F English or Speech

G History or Political Science

$\mathrm{H}$ Languages

I Mathematics-Statistics

J Physical Sciences

K Psychology-Sociology

L Other (than those above)

4. I visit and make some use of the library:
A at least once daily
B almost daily
C more than once a week
D about once a week
E two or three times a month
F about once a month
$\mathrm{G}$ less than once a month

5. Today, my principal reason for coming to the library is to:
A find and read material required for a course
B read library material for self-im- provement
C read for pleasure (or for fun)
D borrow library material for later reading
E do research for a term paper
$\mathrm{F}$ do research for graduate exams or thesis
G do research for a publishable paper or book
$\mathrm{H}$ return books-materials to the library
I get some material copied (Xeroxed)
J do homework with my own books 
$\mathrm{K}$ do something else (not mentioned above)

6. Today, my secondary reason for coming to the library is to:
A find and read material required for a course
B read library material for self-im- provement
C read for pleasure (or for fun)
D borrow library material for later reading
E do research for a term paper
$F$ do research for graduate exams or thesis
G do research for a publishable paper or book
$\mathrm{H}$ return books-materials to the library
I get some material copied (Xeroxed)
J do homework with my own books
$\mathrm{K}$ do something else (not mentioned above)
L do nothing else (I have no second- ary reason)

7. Today, the principal library materials I used were:
A scholarly journals or periodicals
B popular magazines
C newspapers
D reserve books
E reference books
$\mathrm{F}$ dissertations or theses
G microfilm or microform material
$\mathrm{H}$ phonograph records
I books, monographs, individual works
J leisure or "light reading" books
$\mathrm{K}$ not in the list above
L none (I brought own materials)

8. Today the "other" or secondary materials I used were:
A scholarly journals or periodicals
B popular magazines
C newspapers
D reserve books
E reference books
F dissertations or theses
G microfilm or microform material
$\mathrm{H}$ phonograph records
I books, monographs, individual works
J leisure or "light reading" books
$\mathrm{K}$ not in the list above

$\mathrm{L}$ none

9. Today, my success in finding the information and library materials I needed was:
A The question does not apply
B Excellent (found everything)
C Good (found most things)
D Fair (found some things)
E Poor (found few things)
F Very poor (found nothing)

10. Today, the physical condition of the library materials I used was:
A The question does not apply
B Excellent
C Good
D Fair
E Poor
F Very poor

11. Today, the service I received from the librarians and library staff was:
A The question does not apply
B Excellent
C Good
D Fair
E Poor
F Very poor

12. In my experience, the physical condition and the arrangement of the library has been:
A The question does not apply
B Excellent
C Good
D Fair
E Poor
F Very poor

13. Considering all aspects of the library as I have experienced them, I would judge that the library is:
A I have no opinion
B Excellent
C Good
D Fair
E Poor
F Very poor

ANY FURTHER COMMENTS YOU CARE TO MAKE ARE WELCOME. PLEASE WRITE YOUR COMMENTS ON THE REVERSE SIDE OF YOUR IBM CARD. 